\title{
PROPERTY EVALUATION BASED ON AMBIGUOUS LOGIC THROUGH BUILDING INSPECTION IN SÃO PAULO CITY, BRAZIL
}

\author{
*Vladimir Surgelas, Vivita Pukite, Irina Arhipova \\ Latvia University of Life Sciences and Technologies, Latvia \\ *Corresponding author's email: dr.engenho@gmail.com
}

\begin{abstract}
The civil engineering branch is strongly related to the development of the countries and there is still a lot of information available in the buildings constructed. However, these data are dispersed without proper treatment. On the other hand, if these real estate data are reorganized to discover behavior parameters, these properties' values can be predicted and still work as data and causal relationships between explanatory variables. The purpose of the research is to use construction inspection strategies associated with artificial intelligence to predict the market value of a residential apartment. In this academic experiment, only 6 samples of residential apartments are used. Those samples are located in the Lithuania Republic square at Vila Zelina neighborhood, in São Paulo, Brazil, a source in February 2021. The method uses the results of the inspection of civil engineering and converts them into linguistic terms. The result considers the imprecision, uncertainty, and subjectivity of human expression combined with artificial intelligence and civil engineering. To test the feasibility of the process, a comparison is made between the market values of the samples and the values predicted by the Fuzzy logic. Thus, the good results derived a Main Percentage Absolute Error (MAPE) of $5 \%$, the mean absolute error (MAE), root-mean-square error (RMSE), and determination coefficient $\left(\mathrm{R}^{2}\right)$ of 0.99 .
\end{abstract}

Key words: appraisal, algorithmic, civil engineering, inspections, fuzzy logic, baltic countries.

\section{Introduction}

In the Baltic area, the real estate market and civil construction are closely related to each other (Apanaviciene, Urbonas, \& Fokaides, 2020), towards progress and development (Mishra \& Kauškale, 2017). The liberty has been consolidated, as well as the possibility for different choices has become a reality among citizens of the Baltic countries (Gräzin, 2020), added to the process of access to housing that also undergoes changes after the Soviet era (Vihalemm, Juzefovičs, \& Leppik, 2020). In Latvia, there is an academic proposal dealing with improvements in the process of evaluating residential properties with the use of heuristics, artificial intelligence combined with building inspection, and civil engineering techniques (Surgelas, Pukite, \& Arhipova, 2020). By the way, it is relevant in the Baltic since in these countries there is a strong inheritance from a hard time, where individuals for many years had little or no possibility of the choices (Anušauskas et al., 2007). This is because Latvia, Estonia, and Lithuania suffered something similar, the consequences of the Ribbentrop-Molotov Pact, and the World War II reach of the Baltic countries (Bumblauskas et al., 2013; Cadzow, 2020). At the end of the war, Latvia, Lithuania, and Estonia came under the Soviet side of the iron curtain (Baltijos Kelias, 2020; The Baltic Way, 1989-2014). Nonetheless, the heuristic property experimental valuation method was applied in 2019 in Riga city, in 2020 in Jelgava city, both cities located in Latvia. In 2021, the methodology simulation process takes place in Niterói city, Rio de Janeiro and in São Paulo city, in Brazil. In 1982, the Freedom Monument was built in the same square as shows Figure 1. It is a cultural heritage, the commemorative monument for the $50^{\text {th }}$ anniversary of Lithuanian immigration, and a replica of the Freedom Monument in Kaunas, Lithuania. By the way, Lithuania Republic square was chosen in this article because it is a symbolic civic and cultural landmark between Lithuanian, Latvian, and Estonian immigrants. In 2016, the Lithuania Republic square received a proposal to become a civic square Figure 2. Furthermore, that square is a landmark for the sociability of these immigrants and descendants of Lithuanians, Latvians, and Estonians. By the way, heuristics are ideal for solving poorly structured problems (Meech \& Veiga, 1998). In essence, the use of the type of linguistic description employed by human beings, and not quantified variables, allows the treatment of systems that are too complex to be analyzed using conventional mathematical terms. In this context, they also provide acceptable solutions to complex problems. And it is much better if supported by artificial learning algorithms (De Jong, 1988; Agrawal, Rakesh, \& Ramakrishnan, 1994). These heuristics can be solved using Fuzzy logic: that method was introduced by Lotfi A. Zadeh. Besides, from the point of view of logic to fuzzy, the main function of linguistic variables is to provide a systematic way for an approximate characterization of complex or illdefined phenomena. This cognitive heuristic manner influences the decision, which starts to be taken from a balance between reasons for and against the various alternatives (Kirsh, 2009). Because, in the particular case of the real estate market, it has some differentiating characteristics, such as strong influences of the location and heterogeneity of the assets (Cheng, Lin, $\&$ Liu, 2020). These characteristics, once transformed into association rules, can reveal patterns of consumption or sales behavior (Suchacka \& Chodak, 
2017). The process of generating association rules is based on "support" and "confidence". Thus, Weka Software will generate association rules that will present a pattern of behavior, by "apriori" algorithm. Apriori is an algorithm for mining frequent items and learning association rules in relational databases. The algorithm identifies frequent individual items. These sets of frequent items determined by Apriori are used to determine association rules that highlight general trends in the database. Thus, the set of items is considered "frequent" if it meets the support limit specified by the user (Motta, 2010). In this context, the "support" of item "I" is the number of transactions containing "I" divided by the total number of transactions. This "confidence" measures how often items in "Y" appear in transactions that contain " $X$ ". The "confidence" is calculated as the number of transactions containing " $\mathrm{X}$ " and " $\mathrm{Y}$ " divided by the number of transactions containing " $X$ ". Thus, a "strong rule" can be defined as a description of regularity, with high confidence for numerous examples, a "weak rule" represents a regularity with high confidence, for some examples (Rathjens, 1996). Not only, that is, not all rules discovered from a set of transactions are interesting or useful. To assess the degree of interest (IR) of a rule we will have to observe (conf.), (lift), (lev.),(conv.), where: (conf.) is expected confidence. Lift: is the ratio, in percentage terms, between confidence and expected confidence. Likewise,the higher the Lift, the greater the relevance of this rule. Leverage (lev.): indicates the difference between actual and expected support for an association rule. This measure varies between -0.25 and 0.25 , the higher this value, the more interesting the rule will be. Conviction (conv.): it will be used to verify whether the rule obtained using these two measures is relevant. Similar to the confidence measure, conviction represents the associative "power" between the antecedent and the consequent of a rule. Thus, this research is a part of a doctoral thesis in Latvia and the purpose of this article is to use simple building inspection strategies to predict the market price for residential apartments. Moreover, abnormalities taken from inspection (inside) were described with the linguistic terms introduced and Index anomalies. Very light (excellent) $5.00>$ IA $\geq 4.50$; Light (good) $4.50>\mathrm{IA} \geq 3.50$; Medium (medium) $3.50>\mathrm{IA} \geq 2.50$; Serious (bad) $2.50>\mathrm{IA} \geq 1.50$; Very serious (terrible) $1.50>$ IA $\geq 1.00$ (Pedro, Paiva, \& Vilhena, 2008). For this, 6 samples of residential apartments are used in the São Paulo city, Brazil in February 2021. Thus, the process of appraisal is followed by the Fuzzy method (Zadeh, 1965) combined with the incorporation of the association rules originated from Weka's "apriori" algorithm (Frank, Hall, \& Witten, 2017). By the way, the Apriori application is an implementation of Borgelt
(2003), of the traditional Association Rules algorithm, of the same name developed by Agrawal et al. (1993). Further up, in Mandani defuzzification process, the interpretation of the ambiguous set of output inferred carried out, to obtain a numerical value (Srishti \& Seba, 2020). Thus, the InFuzzy software (Posselt, Frozza, \& Molz, 2015) was chosen to discover the prices of the residential flats. Furthermore, Iserhard et al. (2019) suggested the development of quality for performance analysis of a construction company using fuzzy logic. To check the reliability of the method, the comparison between the market values of the samples and the values predicted by the fuzzy logic is used. For this, the Main Percentage Absolute Error - MAPE was calculated.

\section{Materials and Methods}

This research was conducted using as samples 6 residential apartments in São Paulo city during February 2021. The samples contained one until 3 rooms. Then, for a better understanding of the methodology, it was divided into 5 phases described as follow. Phase 1 - Investigation for the data source accessible on the World Wide Web. Residential apartment offers are available on real estate sites in the region under study. After the preselection of samples, the inspection of these samples took place. During the visit to the surveyed properties, the standard engineering inspection form was applied (Fig.3). That form was filled in according to the visual observations available at the time of the technical visit. The variables chosen are a function of the proximity of the Lithuania Republic square and marketplace surrounding of that place, the number of rooms, and the state of condition of the building and apartment. Thus, the variables independents are the following: 1) apartment area (Area), 2) conservation state in the apartment (Consv_ap), 3) building conservation (Consv_build), 4) view to Lithuania Republic square (View), and 5) the number of rooms (rooms). The output $\mathrm{Y}$ is the "Price" of the apartment (Euro $\mathrm{m}^{-2}$ ). Phase 2 - The data were organized by the author to aggregate the attributes of each apartment. The author created the attribute-Relation File Format (ARFF) file on the Notepad++ with the content of the price/square meter ratio. The ARFF is an ASCII text file that describes a list of instances that share a set of attributes. A file ASCII is an essentially raw text, just like the words you are reading now. Phase 3 - The rule system was developed on the basis of the combinations of inputs (total of 5), which were assigned a weight of 1 to establish relevant equality for each rule and reach associations able to optimize the parameters (Abreu et al., 2015). The application of the ARFF file is launched in the Weka software (Frank, Hall, \& Witten, 2017). Thus, the entire process of 


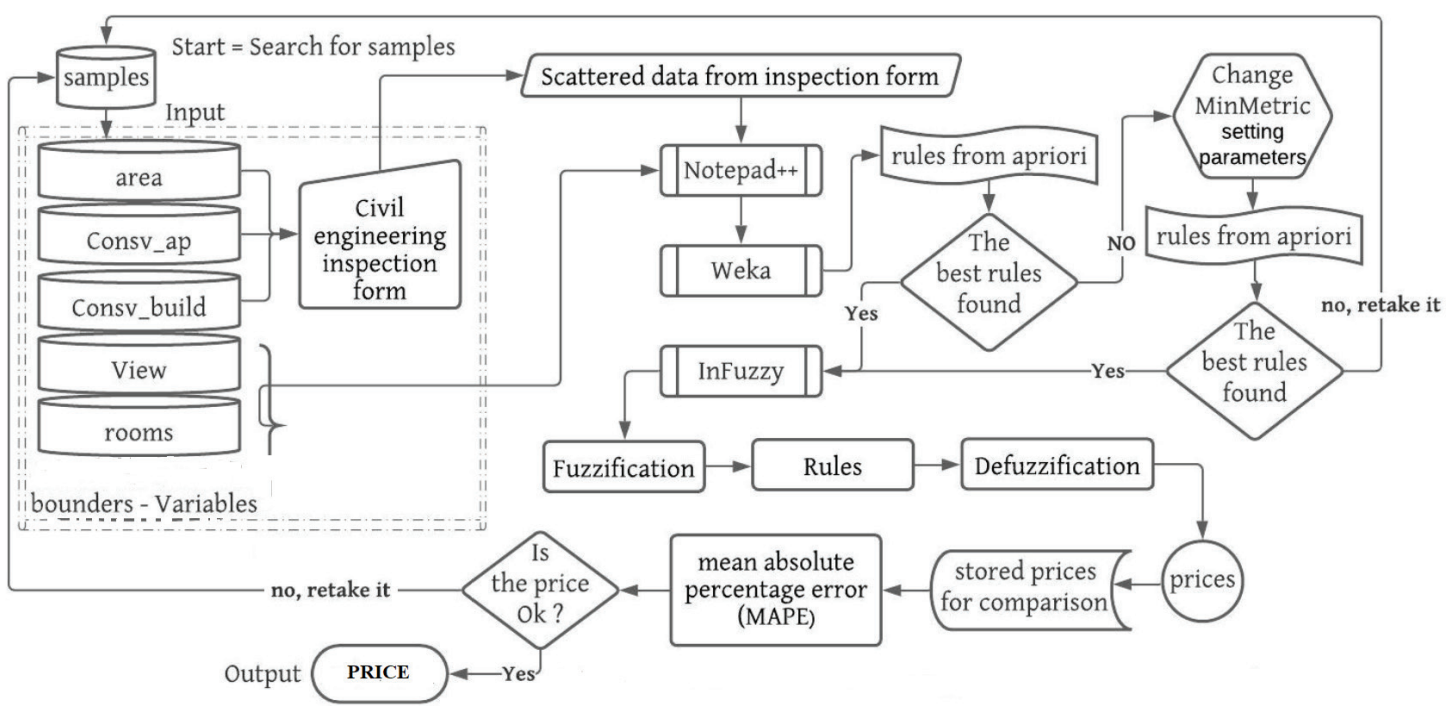

Figure 1. The methodology used for forecasting the 9price of the residential apartment.

Source: author.

generating association rules is based on "support" and "confidence". In this direction, Weka Software will generate association rules that will present a pattern of behavior, by "apriori" algorithm. The support limit was defined by this researcher as $0.25(25 \%)$. That is, the set of frequent items occur together in at least $25 \%$ of all transactions in the database searched in Vila Zelina, in São Paulo (Minimum support: 0.25). The minimum confidence level defined by this researcher was $95 \%$ (Minimum metric < confidence $>$ : 0.95 ). The number of association rules was initially defined by the researcher in 1215 rules (numRules: 1215). Phase 4 - In this phase the InFuzzy software was used, which is a tool for the development of diffuse system applications. In this task, the author inserted the association rules of interest chosen for this research, as selected in Step 3. The Fuzzy sets were done and follow described. For the linguistic variable: 1) (Area) The linguistic terms adopted was a function of the characteristics of the inspected apartments: low, normal, big; The pertinence function chosen was the Gaussian, for which the mean and standard deviation of the sample samples are calculated. Before that, the "Chauvenet" exclusion criterion is adopted. In the base variable, the parameters adopted vary from 0 to 150 mere squares. This is due to the square footage of the surveyed samples not exceeding 130 square meters around Lithuania Republic square. 2) (consv ap) The linguistic terms adopted was a function of the characteristics of the inspected apartments and buildings: terrible, bad, medium, good, excellent. The pertinence function chosen was the left ramp, triangle, right ramp and trapezoidal. In the base variable, the parameters adopted vary from 0 to 5 . These parameters are due to accordingly (Pedro, Paiva, \&
Vilhena, 2008). 3) (consv_build) The linguistic terms adopted was a function of the characteristics of the visual inspected buildings: new, renewed, and old. The pertinence discreet function was chosen. Thus in the base variable, the parameters adopted vary from 1 to 3 . The inspection was visual with an emphasis on the appearance and external condition of the buildings. 4) (view) The linguistic terms adopted was no view, indirect, direct. The pertinence function chosen was the left ramp, triangle and right ramp. Thus in the base variable, the parameters adopted vary from 1 to 3 . This classification attributes the variable "view" to the square as a relevant factor. 5) (rooms) The linguistic terms adopted was small, normal, good. The pertinence function chosen was the discreet. Thus in the base variable, the parameters adopted vary from 1 to 3 . This classification is a function of the typology found during the inspections in the apartments samples, that is, there are samples with 1,2 , and 3 rooms. Phase 5 - The intention of this phase was to understand the precision of the experimental model. It is about reporting the results of step 4 and checking for compatibility. This compatibility and precision of these results were accomplished by the following metrics, the mean percentage absolute error (MAPE). Figure 1 illustrates the methodology used to forecast the price of the residential apartment.

\section{Results and Discussion}

Phase 1 -Selecting scattered data.

Of the six (6) apartments sampled, thirty seven (37) construction items were analyzed visually, involving various specialties within the field of engineering science (Fig.3). Abnormalities observed in the inspection (inside of apartments) were described 
Table 1

Results of inspection on six residential apartments in São Paulo city. Source: author

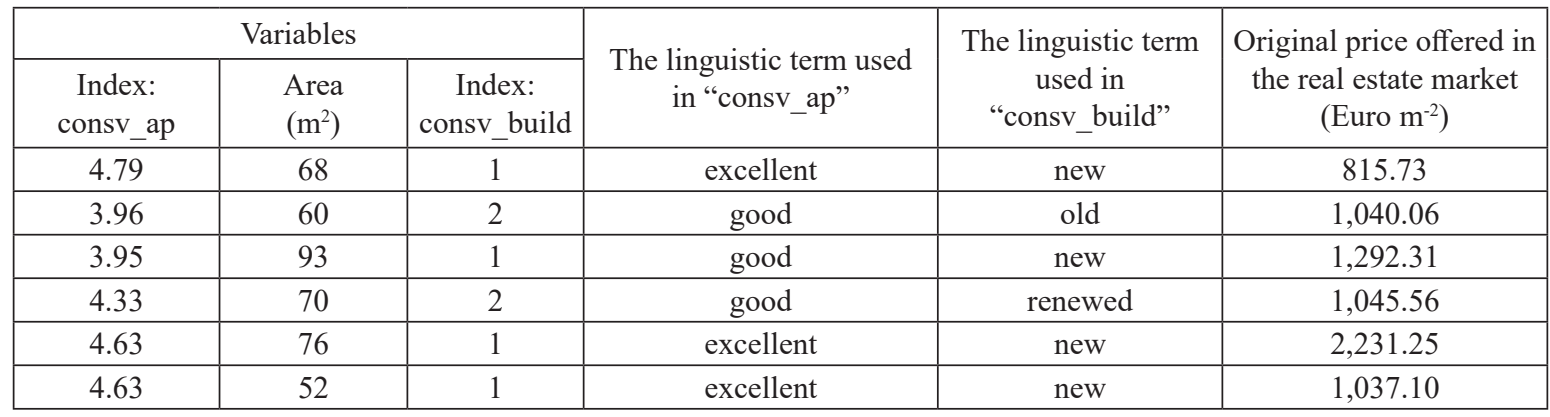
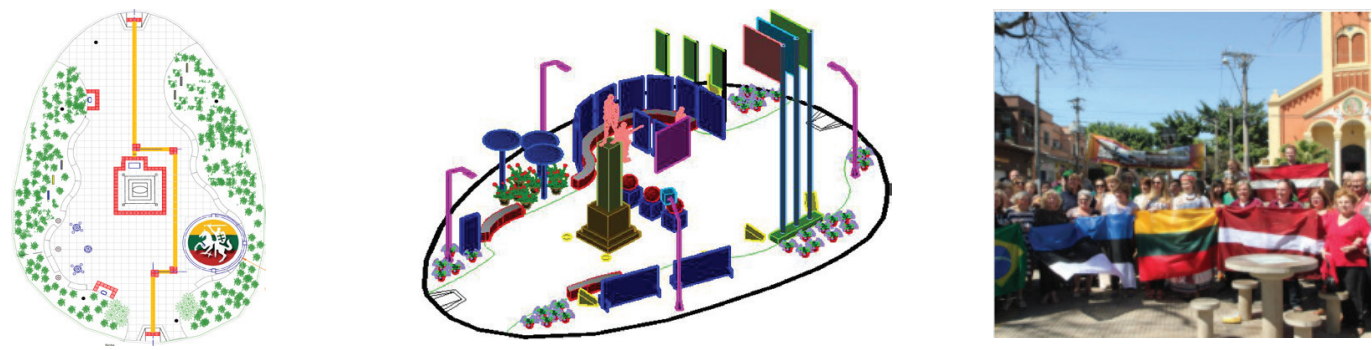

Figure 2. New Civic Square Project.

Source: Architect and Urban Planner Flavia Maria Achão Surgelas, 2016.

linguistic terms. A score of visual problems was created. Very light (excellent) $5.00>\mathrm{IA} \geq 4.50$; Light (good) $4.50>$ IA $\geq 3.50 ;$ Medium (medium) $3.50>$ IA $\geq 2.50$; Serious (bad) $2.50>\mathrm{IA} \geq 1.50$; Very serious (terrible) $1.50>$ IA $\geq 1.00$ according to Pedro, Paiva and Vilhena (2008).

Phase 2 - Preparing files to association rules.

This author created the ARFF file in Notepad ++ with the price / square meter ratio. Below there is the display of the ARFF. This phase had the purpose of preparing the rules for price assessment. Then, phase 3 starts with the rules construction. The rule system was developed on the basis of the combinations of inputs, which were assigned a weight of 1 to establish relevant equality for each rule and reach associations able to optimize the parameters.

Phase 3 - Generating association rules.

By Weka software, with minimum support: 0.25 and minimum confidence level set at 0.95 . So 1,215 rules were generated by the data mining / learning algorithm. In this situation the 67 best rules following in the same confidence level were chosen with "price"

@)relation price_per_square_meter

(a)attribute area_m2 \{normal,big,low

@attribute cons_ap \{terrible,bad,medium,good,excellent (a) attribute cons_build \{new,renewed,old (a) attribute view \{no_view,indirect,direct\} @attribute rooms \{small,normal,good\} (a) attribute price? \{low,average,expensive\} as a conclusion and the system used the InFuzzy rule block. From this, the preselection of the association rules was made and fed the Weka Software. Only then rules can be introduced into the InFuzzy Software. The rule system was developed on the basis of the combinations of inputs, which were assigned a weight of 1 to establish relevant equality for each rule and reach associations able to optimized the parameters.

Phase 4 - Fuzzy Inference process.

The price of the property is assessed, using the InFuzzy software for modelling the diffuse system. Inference was used Mandani methodology. The defuzzification methods were used in Mamdani inference: center of gravity of the area (centroid), method (Dernoncourt, 2013; Abreu et al., 2015). By the analysis of the conventional statistical operation, the parameters of the variable "area" was found after verification by the exclusion criterion "Chauvenet". Chauvenet's criterion brand the premise that the values are in a dataset normally distributed. Hence, five samples were used. For this, the calculation below defines the maximum and minimum values, mean,

@ data

normal,excellent,new,no_view,normal,low

normal,good,old,no_view,normal,average

big,good,new,indirect,good, average

normal,good,renewed,no_view,good,average normal,excellent,new,no_view,normal,expensive

low,excellent,new,no_view,normal,average 


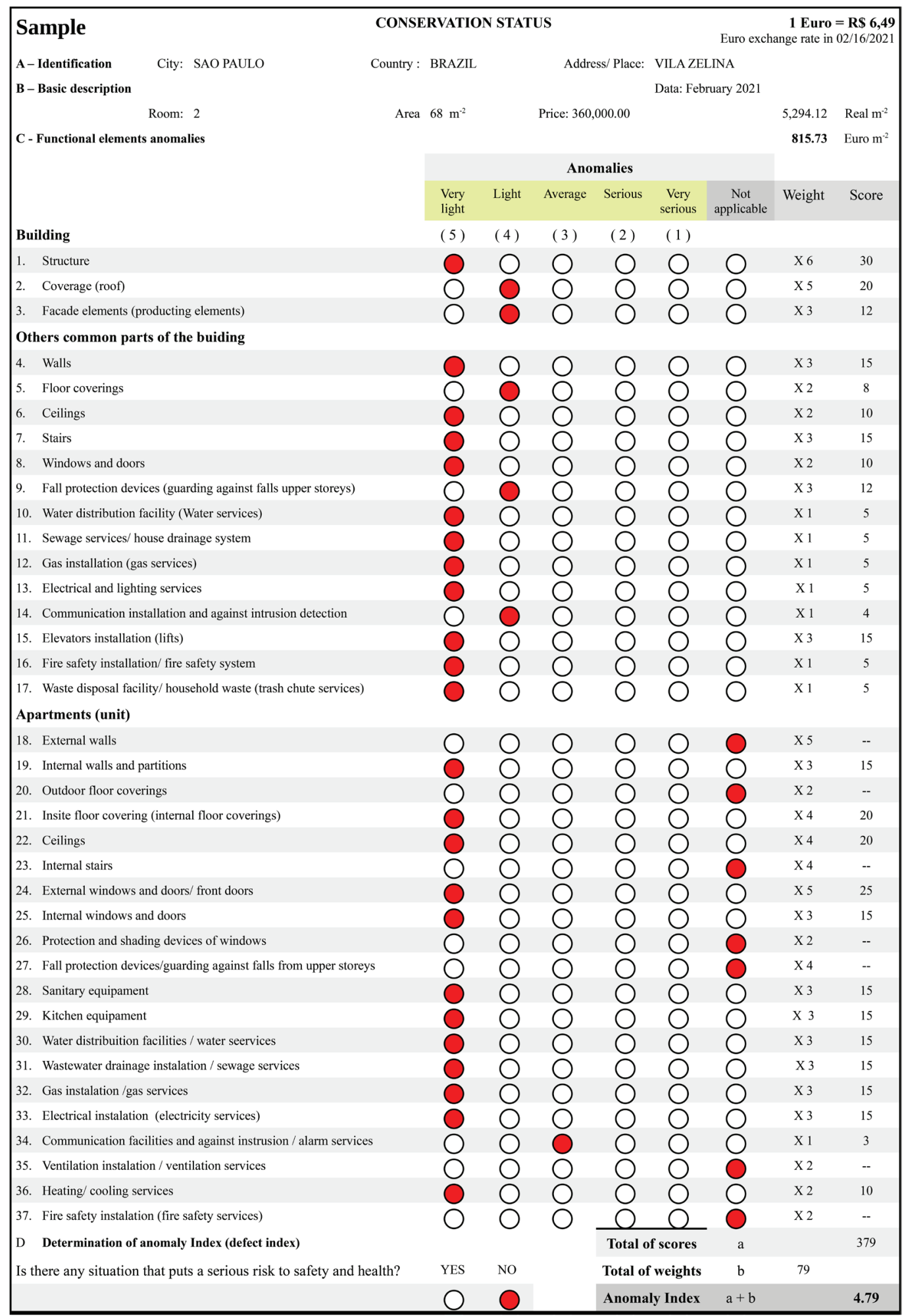

Figure 3. Conservation status form - example: sample 1.

Source: Adapted from (Pedro, Paiva, \& Vilhena, 2008).

the standard deviation of the variable "area". These values were used to write the Gaussian function in the InFuzzy software. Through the Mamdani inference system, the indicators of Gaussian functions were pointed out as better compared to those of triangular functions, regardless of the defuzzification method applied. Table 2 shows an example of the Fuzzy sets. Thus, the computer simulation on In Fuzzy software starts and Table 3 shows the output variable (price) and the result becomes the center of gravity reference 
Summary Fuzzy sets. Source: author

\begin{tabular}{|c|c|c|c|c|c|c|c|}
\hline & Variables & Range & Classification & \multicolumn{3}{|c|}{ Parameters } & Function \\
\hline \multirow{5}{*}{ 言 } & AREA & {$[0,150]$} & $\begin{array}{l}\text { low } \\
\text { normal } \\
\text { big } \\
\end{array}$ & \multicolumn{2}{|c|}{$\begin{array}{c}0.00 \\
69.83 \\
80.23 \\
\end{array}$} & $\begin{array}{c}59.44 \\
14.09 \\
140.00 \\
\end{array}$ & $\begin{array}{c}\text { Left ramp } \\
\text { Gaussian } \\
\text { Right ramp }\end{array}$ \\
\hline & CONSV_AP & {$[0,5]$} & $\begin{array}{l}\text { terrible } \\
\text { bad } \\
\text { medium } \\
\text { good } \\
\text { excellent }\end{array}$ & $\begin{array}{l}1.5 \\
2.5 \\
3.5\end{array}$ & $\begin{array}{l}0.0 \\
2.0 \\
3.0 \\
4.0 \\
4.5\end{array}$ & $\begin{array}{l}1.5 \\
2.5 \\
3.5 \\
4.5 \\
5.0\end{array}$ & $\begin{array}{c}\text { Left ramp } \\
\text { Triangle } \\
\text { Triangle } \\
\text { Trapezoidal } \\
\text { Right ramp }\end{array}$ \\
\hline & CONSV_BUILD & {$[0,3]$} & $\begin{array}{l}\text { new } \\
\text { renewed } \\
\text { old } \\
\end{array}$ & \multicolumn{3}{|c|}{$\begin{array}{l}1 \\
2 \\
3 \\
\end{array}$} & $\begin{array}{l}\text { Discreet } \\
\text { Discreet } \\
\text { Discreet }\end{array}$ \\
\hline & VIEW & {$[0,3]$} & $\begin{array}{l}\text { no view } \\
\text { indirect } \\
\text { direct } \\
\end{array}$ & 0.8 & $\begin{array}{c}0.5 \\
1.65 \\
2.1 \\
\end{array}$ & $\begin{array}{l}1.2 \\
2.5 \\
3.0 \\
\end{array}$ & $\begin{array}{c}\text { Left ramp } \\
\text { triangle } \\
\text { Right ramp }\end{array}$ \\
\hline & ROOMS & {$[0,3]$} & $\begin{array}{l}\text { small } \\
\text { normal } \\
\text { good } \\
\end{array}$ & \multicolumn{3}{|c|}{$\begin{array}{l}1 \\
2 \\
3 \\
\end{array}$} & $\begin{array}{l}\text { Discreet } \\
\text { Discreet } \\
\text { Discreet }\end{array}$ \\
\hline Output & PRICE & {$[0,2200]$} & $\begin{array}{l}\text { low } \\
\text { average } \\
\text { expensive }\end{array}$ & 800 & $\begin{array}{c}150 \\
1350 \\
1900\end{array}$ & $\begin{array}{c}900 \\
2000 \\
2200 \\
\end{array}$ & $\begin{array}{l}\text { Left ramp } \\
\text { Triangle } \\
\text { Right ramp }\end{array}$ \\
\hline
\end{tabular}

Table 3

Simulation in InFuzzy. Analyses were performed using the statistical software Infuzzy. Source: author

\begin{tabular}{|c|c|c|c|c|c|}
\hline area & consv_ap & consv_build & view & room & predicted price \\
\hline 68.00 & 4.79 & 1.00 & 1.65 & 2.00 & $1,383.33$ \\
\hline 60.00 & 3.96 & 2.00 & 0.50 & 2.00 & $1,383.33$ \\
\hline 93.00 & 3.95 & 1.00 & 1.65 & 3.00 & $1,383.33$ \\
\hline 70.00 & 4.33 & 2.00 & 0.50 & 3.00 & $1,383.33$ \\
\hline 76.00 & 4.63 & 1.00 & 0.50 & 3.00 & $1,383.33$ \\
\hline 52.00 & 4.63 & 1.00 & 0.50 & 2.00 & $1,396.94$ \\
\hline
\end{tabular}

Simulation in metric error. Source: author

Table 4

\begin{tabular}{|c|c|c|c|c|c|c|}
\hline price $(\mathrm{Y})$ & price forecast $(\mathrm{Yt})$ & Y-Yt $($ Euro/m²) & $(\mathrm{Y}-\mathrm{Yt}) / \mathrm{Yt}$ & $(Y-Y t)^{2}$ & $\operatorname{abs}(Y-Y t)$ & {$[(\mathrm{Y}-\mathrm{Yt}) / \mathrm{Yt}]^{2}$} \\
\hline 815,73 & 1383,33 & $-567,60$ & $-0,70$ & 322169,76 & 567,6 & 0,48 \\
\hline 1040,06 & 1383,33 & $-343,27$ & $-0,33$ & 117834,29 & 343,27 & 0,11 \\
\hline 1292,31 & 1383,33 & $-91,02$ & $-0,07$ & 8284,64 & 91,02 & 0,00 \\
\hline 1045,56 & 1383,33 & $-337,77$ & $-0,32$ & 114088,57 & 337,77 & 0,10 \\
\hline 2231,25 & 1383,30 & 847,95 & 0,38 & 719019,20 & 847,95 & 0,14 \\
\hline \multirow[t]{4}{*}{1037,10} & 1396,94 & $-359,84$ & $-0,35$ & 129484,83 & 359,84 & 0,12 \\
\hline & & & & 1410881,29 & 2547,45 & $97 \%$ \\
\hline & & & & 272,50 & 134,08 & $5 \%$ \\
\hline & & & & RSME & MAE & MAPE \\
\hline
\end{tabular}


point. The rules association from Weka were written in InFuzzy software. Where:

\begin{tabular}{|c|c|c|c|}
\hline 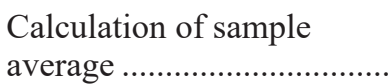 & $(\bar{x})$ & $=$ & $69.83 \mathrm{~m}^{2}$ \\
\hline $\begin{array}{l}\text { The standard deviation of } \\
\text { the sample................................. }\end{array}$ & $(S)$ & $=$ & 14.09 \\
\hline $\begin{array}{l}\text { Sample }- \text { maximum area } \\
\text { found }\end{array}$ & Max & & 93 \\
\hline $\begin{array}{l}\text { Sample }- \text { minimum area } \\
\text { found .................................... }\end{array}$ & Min & & 52.00 \\
\hline Sample numbers .................... & $(n)$ & $=$ & 6 \\
\hline Degrees of freedom ............ & $(n-1)$ & $=$ & $\begin{array}{l}5 \text { (with } 80 \% \\
\text { confidence) }\end{array}$ \\
\hline $\begin{array}{l}\text { Percentile values for } \\
\text { Student's t-distribution....... }\end{array}$ & $(t c)$ & $=$ & $\begin{array}{l}1.65 \text { (table } \\
\text { value) }\end{array}$ \\
\hline
\end{tabular}

$X \operatorname{maxmin}=\bar{x} \pm t c \times\left(\frac{s}{\sqrt{n-1}}\right) \Rightarrow \begin{aligned} & \mathrm{X}_{\max }=80.23 \mathrm{~m}^{2} \\ & \mathrm{X}_{\min }=59.44 \mathrm{~m}^{2}\end{aligned}$

Thus, the defuzzification procedure by centre of mass shows the end process variable (Price at 1,396.94 Euro $\mathrm{m}^{-2}$ )

Phase 5 - Interpretation of the precision of the experimental model.

The result achieved for the prices assessments has a MAPE of approximately around 5\% (Table 4). Furthermore, the experimental data obtained using inspection engineering combined artificial intelligence were used to test the fuzzy models. These prices were compared using the mean absolute error (MAE), root-mean-square error (RMSE), and determination coefficient $\left(\mathrm{R}^{2}\right)$ of 0.99 .

Moreover, the average value of the listed prices of 1,243.67 Euro $\mathrm{m}^{-2}$ is compared with the average price of the fuzzy model of 1,396.94 Euro $\mathrm{m}^{-2}$, it is clear that the system generated differences ranging from $10 \%$ to $12 \%$. In the case of real estate values, this percentage of $10 \%$ to $12 \%$ can be seen as a normal negotiable variation of the price. The main variations in price have significant influence of conservation of the building involving various aspects within the field of engineering. This is therefore, a common practice for negotiation during a sale.

\section{Conclusions}

This research demonstrates that the heuristic knowledge of a civil engineering experiment can be translated into a system to estimate, with the aid of artificial intelligence tools, the price of an apartment in the real estate market. In this sense, the prices obtained by the model using six properties in Vila Zelina, São Paulo, Brazil were very close to those followed by the sellers. Moreover, the linguistic terms obtained in a civil engineering inspection were transformed in indexes and included in inference equations to obtain a conclusion. Consequently, with regard to the linguistic rules of human behavior, this research concludes that the use of fuzzy logic in the evaluation of property prices is a relevant method and generates significant results close to the market reality. Due to the know-how of real estate brokers, the result found in the survey seems very consistent.

\section{References}

Abreu, L.H., Yanagi Junior, T., Fassani, É.J., Campos, A.T., \& Lourençoni, D. (2015). Fuzzy modeling of broiler performance, raised from 1 to 21 days, subject to heat stress. Engenharia Agrícola 35(6): 967-978. DOI: 10.1590/1809-4430-Eng.Agric.v35n6p967-978/2015.

Agrawal, R., Imielinski, T., \& Swami, A.N. (1993). Mining association rules between sets of items in large databases. In P. Buneman \& S. Jajodia (Eds.), Proceedings of the 1993 ACM SIGMOD International Conference on Management of Data, pp. 207-216.

Apanaviciene, R., Urbonas, R., \& Fokaides, P.A. (2020). Smart Building Integration into a Smart City: Comparative Study of Real Estate Development. Sustainability, 12(22), 9376. DOI: 10.3390/su12229376.

Anušauskas, A., Bubnys, A., Kuodyte, D., Jakubčionis, A., Tininis, V., \& Truska, L. (2007). Lietuva 1940-1990: Okupuotus Lietuvos Istorija (Lithuania 1940-1990: History of Occupied Lithuania). Vilnius: Lietuvos Gyventojų Genocido ir Rezistencijo Tyrimo Centras. (in Lithuanian).

Baltijos Kelias. (2020). O caminho do Báltico (The Baltic way). Retrieved February 18, 2021, from http:// comunidadelituana.com.br/index.php/blog-list/52-baltijos-kelias-o-caminho-dob\%C3\%A1ltico.html. (in Portuguese).

Borgelt, C. (2003). Efficient implementations of Apriori and Eclat. In Workshop Frequent Item Set Mining Implementations (FIMI 2003, Melbourne, FL, USA). Retrieved February 27, 2021, from http://fuzzy. cs.uni-magdeburg.de/ borgelt/papers/fimi_03.pdf.

Bumblauskas, A., Eidintas, A., Kulakauskas, A., \& Tamošaitis, M. (2013). Historia de Lithuania (History of Lithuania). Vilnius: UAB BALTO. (in Lithuanian).

Cadzow, J.F. (2020). Lithuanian Americans and Their Communities of Cleveland. Cleveland Memory. 61. Retrieved February 20, 2021, from https://engagedscholarship.csuohio.edu/clevmembks/61. 
Cheng, P., Lin, Z., \& Liu, Y. (2020). Competing Selling Strategies in Housing Market. J Real Estate Finan Econ. DOI: 10.1007/s11146-020-09778-1.

De Jong, K. (1988). Learning with genetic algorithms: An overview. Machine learning, 3(2-3), 121-138.

Dernoncourt, F. (2013). Introduction to fuzzy logic. Retrieved February 27, 2021, from https://www.researchgate. net/publication/267041266_Introduction_to_fuzzy_logic.

Eibe, F., Hall, M.A., \& Witten, I.H. (2017). The WEKA Workbench. in Data Mining, edited by Morgan Kaufmann. pp. 553-71.

Gräzin, I. (2020). EU's Hopeless Crises in Postmodern Reality. East-West Studies, (11).

Iserhard, F.Z., Genro, J.P., Frozza, R., \& Kipper, L.M. (2019). Desdobramento da função qualidade para análise de desempenho de uma empresa de construção civil com o uso de lógica fuzzy (Deployment of the quality function for performance analysis of a construction company using fuzzy logic). Produto \& Produção, 20(1). (in Portuguese).

Kirsh, D. (2009). Problem Solving and Situated Cognition. The Cambridge Handbook of Situated Cognition: 264-306. Retrieved February 02, 2021, from https://philpapers.org/rec/DAVPSA-2.

Meech, J.A., \& Veiga, M.M. (1998). An Adaptive Fuzzy Model to Evaluate Technological Evolution. Minerals Engineering, v.11, n.7, pp. 597-604.

Mishra, A., \& Kauškale, L. (2017). Comparative Analysis of Sustainable Real Estate Market Development in Two Northern Capitals: Case of Riga, Latvia and Stockholm, Sweden, Baltic Journal of Real Estate Economics and Construction Management, 5(1), 186-200. DOI: 10.1515/bjreecm-2017-0014.

Motta, Custódio Gouvêa Lopes da. (2010). Metodologia para Mineração de Regras de Associação Multiníveis Incluindo Pré e Pós-Processamento (Methodology for Mining Multilevel Association Rules, Including Pre- and Post-Processing). Rio de Janeiro: UFRJ/COPPE. XIII, 90 p.: il.; 29,7 cm. Tese (doctorate degree) - UFRJ/ COPPE/ Programa de Engenharia Civil. Retrieved February 27, 2021, from www.coc.ufrj.br. (in Portuguese).

Pedro, J.A.C.B.O., de Paiva, J.A.V., \& Vilhena, A.J.D.S.M. (2008). Portuguese Method for Building Condition Assessment. Structural Survey 26(4).

Posselt, E., Frozza, R., \& Molz, R. (2015). INFUZZY: Ferramenta para desenvolvimento de aplicações de sistemas difusos (INFUZZY: Tool for developing diffuse system applications). Revista Brasileira de Computação Aplicada. 7, 1 (fev. 2015), 42-52. DOI: 10.5335/rbca.2015.3960. (in Portuguese).

Rathjens, D. (1996). MineSet User's Guide. Silicon Graphics, Inc. Retrieved February 27, 2021, from https:// techpubs.jurassic.nl/library/manuals/3000/007-3214-002/pdf/007-3214-002.pdf.

Srishti, V., \& Seba, S. (2020). Inferring Sentiments from Supervised Classification of Text and Speech cues using Fuzzy Rules, Procedia Computer Science, Volume 167, pp. 1370-1379. ISSN 1877-0509. DOI: 10.1016/j.procs.2020.03.348.

Suchacka, G., \& Chodak, G. (2017). Using association rules to assess purchase probability in online stores Inf Syst E-Bus Manage 15, 751-780. DOI: 10.1007/s10257-016-0329-4.

Surgelas, V., Pukite, V., \& Arhipova, I. (2020). Improvements in the civil engineering focused on the real estate appraisal with the use of artificial intelligence and fuzzy logic. Baltic Surveying. 12. 44-52. DOI: 10.22616/j.balticsurveying.2020.007.

The Baltic Way 1989-2014. History. Retrieved September 25, 2019, from http:/www.thebalticway.eu/en/ history/.

Vihalemm, T., Juzefovičs, J., \& Leppik, M. (2019). Identity and Media-use Strategies of the Estonian and Latvian Russian-speaking Populations Amid Political Crisis, Europe-Asia Studies, 71:1, 48-70, DOI: 10.1080/09668136.2018.1533916.

Zadeh, L.A. (1965). Fuzzy sets. Information and Control 8 (3) 338-353. Retrieved February 27, 2021, from http://www.cs.berkeley.edu/ zadeh/papers/Fuzzy Sets-Information and Control-1965.pdf. 